\title{
Demand Side Management of a Run-of-Mine Ore Milling Circuit
}

\author{
B. Matthews ${ }^{\mathrm{a}}$, I.K. Craiga,* \\ ${ }^{a}$ Department of Electrical, Electronic, and Computer Engineering, University of \\ Pretoria, Pretoria, South Africa.
}

\begin{abstract}
Increasing electricity costs coupled with lower prices for some metals such as platinum group metals, require a reevaluation of the operation of grinding processes. Demand side management (DSM) has received increasing attention in the field of industrial control as an opportunity to reduce operating costs. DSM through grinding mill power load shifting is presented in this paper using model predictive control and a real-time optimizer. Simulation results indicate that mill power load shifting can potentially achieve cost reductions of $\$ 9.90 / \mathrm{kg}$ of unrefined product when applied to a run-of-mine (ROM) ore milling circuit processing platinum bearing ore. DSM is however still not economically feasible when there is a demand to continuously run the milling circuit at maximum throughput.

Keywords: Demand side management, Milling circuit, Model predictive control, Power load shifting, Real-time optimizer, Time-of-use tariff
\end{abstract}

\footnotetext{
${ }^{*}$ Corresponding author. Address: Department of Electrical, Electronic, and Computer Engineering, University of Pretoria, Pretoria, South Africa.

Tel.: +27 12420 2172; fax: +27 123625000 .

Email address: icraig@postino.up.ac.za (I.K. Craig)
} 


\section{Introduction}

As energy costs increase, the operating procedures of energy intensive processes should be reevaluated in order to find cost saving opportunities. One such process is the run-of-mine (ROM) ore milling circuit used in the mineral processing industry.

ROM ore milling circuits are used for primary grinding of ore so that valuable minerals within the ore can be liberated, separated, and concentrated in downstream processes (Hodouin, 2011). ROM ore milling circuits have been identified as the most energy intensive unit processes in a mineral processing plant (Wei \& Craig, 2009a).

In addition to being an energy intensive process, ROM ore milling circuits are also complicated processes to control. Difficulties in the control of ROM ore milling circuit result from integrating features with strong disturbances, large time delays, non-linearities, and strong interactions (Coetzee, 2009). The fineness of the milling circuit product is used as a measure of its quality (Muller \& De Vaal, 2000) and is a major determinant of the effectiness of downstream separation and concentration processes (Craig et al., 1992).

The concept of demand side management (DSM) was formalized in the 1980s by Gellings (1985). DSM presents a shift from the traditional supplydemand strategy of electricity load control as it encourages customers to assist in electricity load control by managing demand. This management of demand allows customers to indirectly control the load shape of the utility.

Demand side management projects can be categorized as energy efficiency, time-of-use (TOU), demand response, and spinning reserve projects (Palensky \& Dietrich, 2011). Time-of-use tariffs are used by electricity utilities to 
encourage consumers to move their demand from peak periods to off-peak periods by using different tarrifs for the respective periods.

Load shifting as a DSM technique has received increasing attention in recent years as electricity utilities encourage customers to reduce peak demands. Load shifting is performed in response to the TOU tariffs implemented by utilities. Reduced peak demands result in less stress on power generation facilities during peak periods and help maintain a stable reserve margin (Palensky \& Dietrich, 2011).

While the mining sector accounts for approximately $15 \%$ of electricity consumption in South Africa (Eskom, 2012a), little has been published in the open literature on the implementation of DSM in the sector.

DSM techniques that have been studied within the mining sector include hoist scheduling techniques for a deep level mine (Badenhorst et al., 2011), scheduling techniques for water pumping in underground mines (van Staden et al., 2011), and an optimal control model for conveyors in a colliery (Middelberg et al., 2009). These studies have shown that operating costs associated with electricity consumption may be reduced by shifting the load according to TOU tariffs.

DSM, specifically load shifting, presents an opportunity for the control community to contribute to profitability improvements of processes. Projects aimed at retrofitting older plant equipment with new energy efficient equipment are associated with capital expenditure and often long payback periods which discourage the implementation of such projects. Implementation of load shifting projects require less capital expenditure while offering potential reduction of operating expenditure (Bauer \& Craig, 2008). 
Traditionally ROM ore milling circuits have been controlled to achieve maximum throughput as the cost of electricity was low. Electricity has however become increasingly expensive. This paper focuses on the production of platinum group metals (PGMs) of which South Africa produced approximately $75 \%$ of the total world output in 2011 (Jansen, 2012). The cost of electricity in South Africa has increased by an average $27 \%$ for the period 2008-2012 (Eskom, 2012a; NERSA, 2012), and all indications are that annual double digit increases will be applied for the foreseeable future.

A number of studies in the optimization of milling circuits have been performed at the supervisory control layer. An expert system based on IF-THEN logic was developed to optimize mill power in order to achieve maximum throughput on a milling circuit (Borell et al., 1996). A fuzzy logic rule-based supervisory controller was developed to achieve the maximum transfer of energy to the mill charge (Steyn et al., 2010). An on-line economic performance optimizer was also developed, but the cost of energy was not considered in the economic objective function (Radhakrishnan, 1999).

The traditional control of ROM ore milling circuits must therefore be reevaluated to determine whether operating at maximum throughput remains effective. An implementation of mill power load shifting to realize a reduction of operating costs associated with electricity consumption is therefore developed. This reduction of operating expenditure is also evaluated against the performance of a ROM ore milling circuit controller that does not take DSM into account. 


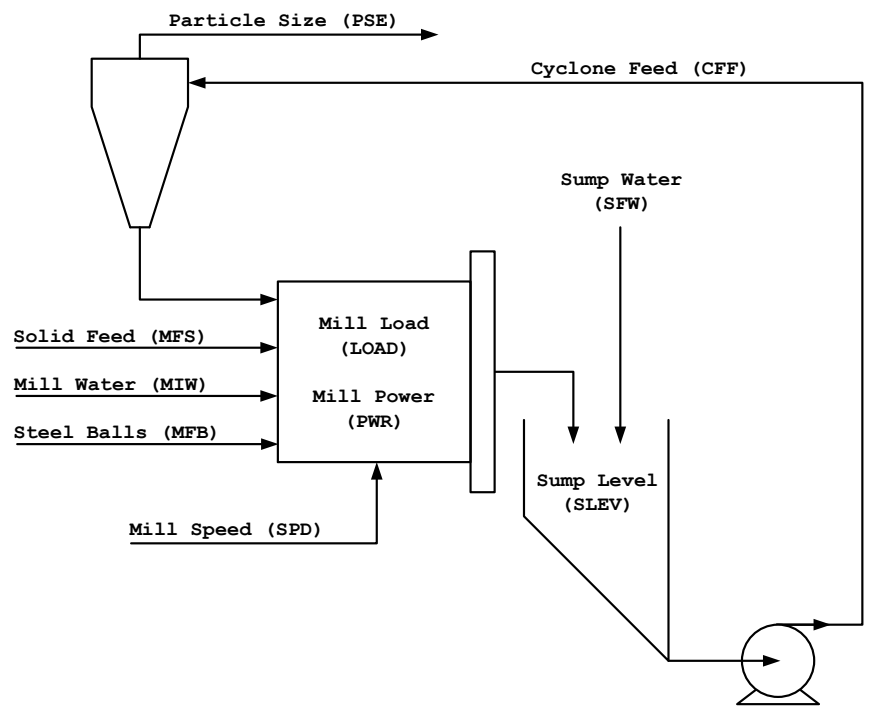

Figure 1: ROM ore milling circuit adapted from Coetzee et al. (2010).

\section{ROM ore milling circuit}

\subsection{Introduction}

The ROM ore milling circuit (see Fig. 1) used for this study consists of a semi-autogenous (SAG) mill, a sump, and a hydrocyclone. Grinding occurs within the SAG mill using steel balls and the ore. Water is pumped into the mill to create a slurry to promote grinding and flow through the mill. The sump is used to adjust the density of the slurry and acts as a buffer in the circuit. The hydrocyclone is used to split in-specification material from the out-of-specification material.

Ore is fed to the SAG mill at approximately $90 \mathrm{t} / \mathrm{h}$. The ore is mixed with feed water, steel balls, and underflow from the cyclone. A slurry is formed within the mill which can be classified into coarse ore, fines, and water as described in Section 2.2. Fines are classified as particles within specification, 
specifically smaller than $75 \mu \mathrm{m}$. Coarse ore is classified as particles out-ofspecification. The slurry leaves the mill through a discharge grate at the end of the mill and is fed into a sump.

In the sump water is added to dilute the slurry to achieve a desired density and to facilitate transport through the circuit. The diluted slurry is then pumped to the hydrocyclone. The hydrocyclone splits the particles in the slurry so that approximately $80 \%$ of the overflow stream is made up of fines. The overflow stream is sent to downstream separation and concentration processes. The underflow consists primarily of coarse ore which is fed back to the mill for regrinding.

Separation of the liberated product of a milling circuit can be achieved using e.g. flotation or leaching. For this study it is assumed that the PGMs are separated using a flotation circuit (Hodouin, 2011). The recovery of PGMs in the separation stage is dependent on the product particle size produced by the milling circuit i.e. the cyclone overflow. The relationship between PGM recovery and particle size used for this study is given in Fig. 2.

\subsection{Milling circuit model}

A non-linear model was developed for the milling circuit as described in Coetzee et al. (2010) and Le Roux et al. (2012). The non-linear model was validated using real plant data as described in Le Roux et al. (2012). The model is made up of four modules that together simulate the closed loop milling circuit. The modules are a feeder, mill, sump, and hydrocyclone module.

The feeder module is used to combine the solids feed, mill inlet water

feed, and ball feed with the underflow of the cyclone which are all fed to the 


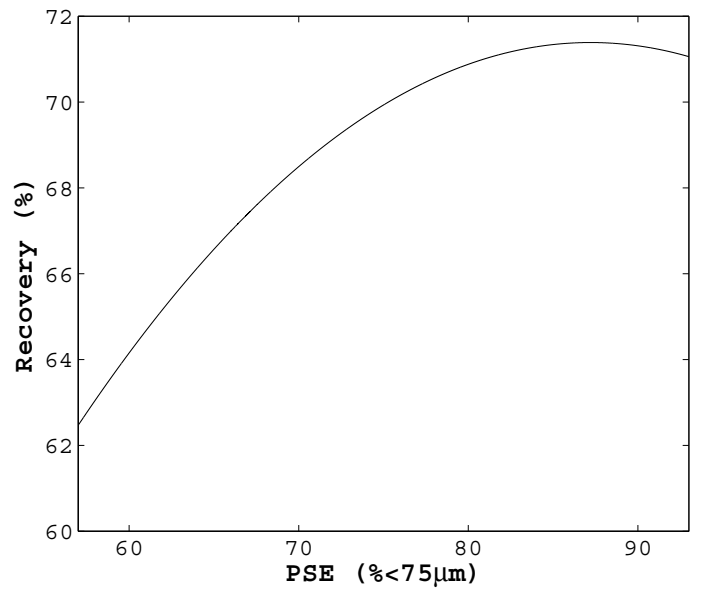

Figure 2: Recovery as a function of particle size, adapted from Wei \& Craig (2009b).

mill. The mill module is used to simulate the grinding action within the mill. The sump module is used to simulate the state of the sump and the cyclone module is used to simulate the classification process within the hydrocyclone.

For this study the mill module is of particular interest as it is mill power draw that will be shifted according to TOU tariffs. The mill power draw model originates from the mill module and will be discussed here. A full discussion of the modules is given in Coetzee et al. (2010) and Le Roux et al. (2012) and will not be repeated here.

The mill power model is a function of mill load, the mill rheology factor, and the fraction of critical mill speed, referred to from here on as mill speed (SPD). Mill load is defined as the fraction of the mill filled, and the rheology factor is used to describe the fluidity of the slurry based on the mill states. 
Table 1: Mill model parameters

\begin{tabular}{|c|c|c|}
\hline Variable & Nom & Description \\
\hline$\varepsilon_{w s}$ & 0.6 & $\begin{array}{l}\text { Maximum water-to-solids volumetric ratio at } \\
\text { zero slurry flow. }\end{array}$ \\
\hline$P_{\max }$ & 2000 & Maximum mill motor power. $[\mathrm{kW}]$ \\
\hline$\delta_{P v}$ & 1 & Power-change parameter for volume. \\
\hline$v_{P_{\max }}$ & 0.45 & $\begin{array}{l}\text { Fraction of mill volume filled for maximum } \\
\text { power. }\end{array}$ \\
\hline$\delta_{P_{s}}$ & 1 & Power-change parameter for fraction solids. \\
\hline$\varphi_{P_{\max }}$ & 0.51 & Rheology factor for maximum mill power. \\
\hline$\alpha_{P}$ & 0.82 & $\begin{array}{l}\text { Fraction power reduction per fractional reduc- } \\
\text { tion from maximum mill speed. }\end{array}$ \\
\hline$v_{\text {mill }}$ & 100 & Mill volume $\left[\mathrm{m}^{3}\right]$ \\
\hline$\chi_{P}$ & 0 & Cross-term for maximum power. \\
\hline
\end{tabular}

The rheology factor is given by

$$
\varphi=\sqrt{\frac{\max \left[0,\left(X_{m w}-\left(1 / \varepsilon_{w s}-1\right) \cdot X_{m s}\right)\right]}{X_{m w}}} .
$$

The effect of rheology on power consumption is given by

$$
Z_{r}=\frac{\varphi}{\varphi_{P_{\max }}}-1
$$

and the effect of mill load on power consumption is given by

$$
Z_{x}=\frac{X_{m w}+X_{m s}+X_{m r}+X_{m b}}{v_{P_{\text {max }}} \cdot v_{m i l l}}-1 .
$$

Mill power consumption is given by

$$
\begin{aligned}
& P W R=P_{\max } \cdot\left\{1-\delta_{P_{v}} \cdot Z_{x}^{2}\right. \\
& \left.-2 \cdot \chi_{P} \cdot \delta_{P_{v}} \cdot \delta_{P_{s}} \cdot Z_{x} \cdot Z_{r}-\delta_{P_{s}} \cdot Z_{r}^{2}\right\} \cdot(S P D)^{\alpha_{P}} .
\end{aligned}
$$

The parameters used for the mill model are given in Table 1. The states of the milling circuit are given in Table 2. The states of the mill are the holdups of water $\left(X_{m w}\right)$, ore $\left(X_{m s}\right)$, fine ore $\left(X_{m f}\right)$, rocks $\left(X_{m r}\right)$, and steel balls $\left(X_{m b}\right)$. The states of the sump are the holdups of water $\left(X_{s w}\right)$, ore 
Table 2: Milling circuit states

\begin{tabular}{|c|c|c|c|c|}
\hline Variable & Min & Max & OP & Description \\
\hline$X_{m w}$ & 0 & 50 & 8.01 & $\begin{array}{l}\text { The holdup of water in the } \\
\text { mill. }\left[\mathrm{m}^{3}\right]\end{array}$ \\
\hline$X_{m s}$ & 0 & 50 & 8.78 & $\begin{array}{l}\text { The holdup of ore in the } \\
\text { mill. }\left[\mathrm{m}^{3}\right]\end{array}$ \\
\hline$X_{m f}$ & 0 & 50 & 3.24 & $\begin{array}{l}\text { The holdup of fine ore in } \\
\text { the mill. }\left[\mathrm{m}^{3}\right]\end{array}$ \\
\hline$X_{m r}$ & 0 & 50 & 16.98 & $\begin{array}{l}\text { The holdup of rock in the } \\
\text { mill. }\left[\mathrm{m}^{3}\right]\end{array}$ \\
\hline$X_{m b}$ & 0 & 20 & 6.22 & $\begin{array}{l}\text { The holdup of balls in the } \\
\text { mill. }\left[\mathrm{m}^{3}\right]\end{array}$ \\
\hline$X_{s w}$ & 0 & 30 & 15.14 & $\begin{array}{l}\text { The holdup of water in the } \\
\text { sump. }\left[\mathrm{m}^{3}\right]\end{array}$ \\
\hline$X_{s s}$ & 0 & 30 & 3.43 & $\begin{array}{l}\text { The holdup of ore in the } \\
\text { sump. }\left[\mathrm{m}^{3}\right]\end{array}$ \\
\hline$X_{s f}$ & 0 & 30 & 1.26 & $\begin{array}{l}\text { The holdup of fine ore in } \\
\text { the sump. }\left[\mathrm{m}^{3}\right]\end{array}$ \\
\hline
\end{tabular}

$\left(X_{s s}\right)$, and fine ore $\left(X_{s f}\right)$. The holdup of ore $\left(X_{m s}\right.$ and $\left.X_{s s}\right)$ is considered the holdup of in-specification ore (fine ore) plus out-of-specification ore (coarse ore). The steady-state operating points of the states are also given in Table 2.

\subsection{Control objectives}

Run-of-mine ore milling circuits are inherently difficult processes to control. They exhibit integrating features with strong external disturbances, large time delays, non-linearities, and strong interactions (Coetzee, 2009). The control of milling circuits using model predictive control (MPC) has however been shown to be effective (Muller \& De Vaal, 2000; Coetzee et al., 2010; Niemi et al., 1997; Ramasamy et al., 2005; Chen et al., 2007, 2008).

Traditionally the control objectives for a ROM ore milling circuit can be given as (Craig \& MacLeod, 1995)

1. improve the quality of the product by increasing the fineness of the grind and decreasing product size fluctuations, 
Table 3: Milling circuit CVs and MVs

\begin{tabular}{|c|c|c|c|c|c|}
\hline Variable & Min & Max & OP & $\mathrm{W}$ & Description \\
\hline \multicolumn{6}{|c|}{ Controlled variables } \\
\hline PSE & 60 & 90 & 82.0 & 200 & $\begin{array}{l}\text { Product particle } \\
\text { size. }[\%<75 \mu \mathrm{m}]\end{array}$ \\
\hline LOAD & 30 & 50 & 40.0 & 10 & $\begin{array}{l}\text { Percentage of the } \\
\text { mill filled. [\%] }\end{array}$ \\
\hline SLEV & 2 & 38 & 18.6 & 8 & $\begin{array}{l}\text { Level of the sump } \\
{\left[\mathrm{m}^{3}\right]}\end{array}$ \\
\hline PWR & 0 & 2000 & 1855 & 200 & $\begin{array}{l}\text { Power draw of the } \\
\text { mill motor. }[\mathrm{kW}]\end{array}$ \\
\hline $\mathrm{TPT}$ & 0 & 200 & 92.0 & - & $\begin{array}{l}\text { Throughput (con- } \\
\text { sists of coarse and } \\
\text { fine solids). }[\mathrm{t} / \mathrm{h}]\end{array}$ \\
\hline \multicolumn{6}{|c|}{ Manipulated variables } \\
\hline $\mathrm{CFF}$ & 400 & 500 & 470.4 & $10^{-5}$ & $\begin{array}{l}\text { Flow-rate of slurry } \\
\text { from the sump to } \\
\text { the cyclone. }\left[\mathrm{m}^{3} / \mathrm{h}\right]\end{array}$ \\
\hline MFS & 0 & 200 & 92.0 & $10^{-4}$ & $\begin{array}{l}\text { Feed-rate of ore to } \\
\text { the circuit. }[\mathrm{t} / \mathrm{h}]\end{array}$ \\
\hline MIW & 0 & 100 & 30.7 & - & $\begin{array}{l}\text { Flow-rate of water } \\
\text { to the mill. }\left[\mathrm{m}^{3} / \mathrm{h}\right]\end{array}$ \\
\hline SFW & 0 & 400 & 304.3 & $10^{-5}$ & $\begin{array}{l}\text { Flow-rate of water } \\
\text { to the sump. }\left[\mathrm{m}^{3} / \mathrm{h}\right]\end{array}$ \\
\hline SPD & 70 & 100 & 92.7 & 1 & $\begin{array}{l}\text { Percentage of criti- } \\
\text { cal mill speed. [\%] }\end{array}$ \\
\hline MFB & 0 & 4 & 2 & - & $\begin{array}{l}\text { Feed-rate of balls to } \\
\text { the mill. }[\mathrm{t} / \mathrm{h}]\end{array}$ \\
\hline
\end{tabular}

2. maximize throughput,

3. minimize consumption of grinding media, and

4. minimize power consumption

The control objectives are however not all complementary and therefore require certain trade-offs. A frequently applied trade-off is to rather maximize throughput than minimize power consumption. This trade-off is often applied owing to the high value of the product compared to the traditionally low cost of electricity in South Africa (Coetzee, 2009).

In recent years the cost of electricity has significantly increased in South 
Africa and will continue increasing (Eskom, 2012a; NERSA, 2012) as indicated earlier. In addition to the cost of electricity increasing, the reserve margins have decreased, resulting in a less reliable supply. The control objectives for the mill power load shifting controller were therefore updated to the following:

1. maintain milling circuit stability,

2. maintain a constant product size and decrease product size fluctuations around this value,

3. maintain a specified average throughput over a seven day horizon, and

4. minimize the costs associated with power consumption.

\subsection{Controlled and manipulated variables}

Traditionally the controlled variables $(\mathrm{CVs})$ for a $\mathrm{ROM}$ ore milling circuit are product particle size (PSE), the percentage of the mill volume filled (LOAD), and sump level (SLEV). The manipulated variables (MVs) most commonly used to control the milling circuit are the flow-rate of water to the mill (MIW), the feed-rate of ore to the circuit (MFS), the flow rate of slurry from the sump to the cyclone $(\mathrm{CFF})$, and the flow-rate of water to the sump (SFW) (Wei \& Craig, 2009a; Coetzee et al., 2010; Olivier et al., 2012).

Owing to the trade-off between throughput and power, mill power is generally not controlled directly (Coetzee, 2009). In order to perform mill power load shifting on the milling circuit, mill power (PWR) must however be added as a CV. PSE is controlled as the product quality of a ROM ore milling circuit is related to PSE. Mill load and sump level have integrating characteristics and must therefore be controlled to maintain milling circuit stability. 
The traditional MVs are used to control the milling circuit in this study with mill speed (SPD) added to achieve functional controllability (Skogestad $\&$ Postlethwaite, 2005). The flow-rate of water to the mill (MIW) is ratio controlled to the feed-rate of ore to the circuit in order to maintain a relatively constant solids-to-water ratio within the mill.

The addition of balls to the milling circuit is often performed manually and the feed-rate of balls to the mill (MFB) is therefore not used as an MV. MFB is kept constant at the nominal value of $2 \mathrm{t} / \mathrm{h}$. Based on the mill power model, mill power can be controlled by manipulating the hold-up within the mill, the rheology factor, and mill speed (SPD). Mill speed has the most direct effect on mill power and is therefore used as an MV.

In a recent survey that addressed the control of grinding mill circuits, $90 \%$ of the respondents reported that an electric motor is typically used as the actuator for mill speed (Wei \& Craig, 2009b). In order to use mill speed as an MV it is necessary to have a variable speed drive (VSD) to regulate the speed of the mill motor. For this study it is assumed that such a VSD is available.

The controlled and manipulated variables of the milling circuit are given in Table 3. The operating range, operating point, and controller weighting of each of the variables are also presented in the table. The controller weightings are further discussed in Section 3.2.

\section{Regulatory control}

Model predictive controllers have been shown to perform better than single loop PI(D) controllers for ROM ore milling circuits (Muller \& De Vaal, 
2000; Coetzee et al., 2010; Niemi et al., 1997; Ramasamy et al., 2005; Chen et al., 2007, 2008). Following recent trends a linear model predictive controller was developed to stabilize the system and implement mill power load shifting at the regulatory control level.

\subsection{Linear model}

In this paper the non-linear plant model described in Section 2.2 is controlled using a linear model predictive controller. A linear model was derived by performing system identification (SID) on the non-linear model around the operating point given in Table 2 (Ljung, 1999). The linear model is given by

$$
\left[\begin{array}{c}
\triangle P S E \\
\triangle L O A D \\
\Delta S L E V \\
\Delta P W R
\end{array}\right]=\left[\begin{array}{llll}
g_{11} & g_{12} & g_{13} & g_{14} \\
g_{21} & g_{22} & g_{23} & g_{24} \\
g_{31} & g_{32} & g_{33} & g_{34} \\
g_{41} & g_{42} & g_{43} & g_{44}
\end{array}\right]\left[\begin{array}{c}
\Delta C F F \\
\Delta M F S \\
\Delta S F W \\
\Delta S P D
\end{array}\right]
$$

All transfer functions are given with time constants in hours. The transfer functions between PSE and the MVs as given in (5) are

$$
\begin{aligned}
& g_{11}(s)=\frac{6.994 \times 10^{-3}(2.188 s-1)}{(0.432 s+1)} e^{-0.011 s}, \\
& g_{12}(s)=\frac{-9.478 \times 10^{-2}}{(0.483 s+1)} e^{-0.064 s}, \\
& g_{13}(s)=\frac{4.481 \times 10^{-2}}{(0.339 s+1)} e^{-0.011 s}, \\
& g_{14}(s)=\frac{0.108}{(0.574 s+1)} e^{-0.014 s} .
\end{aligned}
$$


The transfer functions between LOAD and the MVs are

$$
\begin{aligned}
& g_{21}(s)=\frac{1.770 \times 10^{-2}(9.728 s+1)}{s(0.817 s+1)}, \\
& g_{22}(s)=\frac{9.556 \times 10^{-2}}{s}, \\
& g_{23}(s)=\frac{-1.444 \times 10^{-2}(8.850 s+1)}{s(0.663 s+1)}, \\
& g_{24}(s)=\frac{-1.050}{(7.2 s+1)} .
\end{aligned}
$$

The transfer functions between SLEV and the MVs are

$$
\begin{aligned}
& g_{31}(s)=\frac{-0.769}{s}, \\
& g_{32}(s)=\frac{0.876}{s}, \\
& g_{33}(s)=\frac{0.677}{s}, \\
& g_{34}(s)=\frac{-0.883}{s} .
\end{aligned}
$$

The transfer functions between PWR and the MVs are

$$
\begin{aligned}
g_{41}(s) & =\frac{3.577(1.610 s+1)}{(6.329 s+1)} e^{-0.014 s,} \\
g_{42}(s) & =\frac{8.990}{(1.93 s+1)}, \\
g_{43}(s) & =\frac{1.605(0.0075 s+1)}{(0.782 s+1)} e^{-0.014 s}, \\
g_{44}(s) & =\frac{73.57(9.643 s+1)}{(4.576 s+1)(0.001 s+1)} .
\end{aligned}
$$

The linear plant model was identified through SID using step response data generated by the non-linear plant model. First order transfer functions with time delay were fitted to the step response data. Where the first order 
transfer functions did not produce an accurate fit, a zero was added to the model form to improve the fit.

The PWR/SPD transfer function, $g_{44}(s)$, however does not conform to the general model form as it has a single zero in an overdamped second-order transfer function. Analytically it can be argued that for $\left(\tau_{p 1}=4.576\right) \gg$ $\left(\tau_{p 2}=0.001\right)$, setting $\tau_{p 2} \rightarrow 0$ gives a similar response. This simplification however results in a poor model for PWR/SPD. The time constant $\tau_{p 2}=$ 0.001 relates to the fast initial response of PWR as SPD is changed as can be identified in (4).

As mill speed changes the states within the mill begin to change. The time constants $\tau_{p 1}=4.576$ and $\tau_{z}=9.643$ therefore relate to the decay of mill power as the effect of rheology on mill power, $Z_{r}$, and the effect of mill load on mill power, $Z_{x}$, begin to change (see (2) and (3)). The fit of the PWR/SPD transfer function compared to the step response validation data is presented in Fig. 3.

The fit of all the models are not presented in this paper owing to space constraints. The models are however similar to those presented by Hulbert et al. (1990) for a ROM ore milling circuit.

\subsection{Model predictive controller}

The MPC controller was designed using the linear model from (5) to control the non-linear plant model described in Section 2.2. The objective of the controller is given by

$$
\begin{gathered}
\min _{\mathbf{u}} V\left(\mathbf{u}, \mathbf{x}_{0}\right), \\
\text { s.t. } \mathbf{y} \in \mathbb{Y}, \mathbf{u} \in \mathbb{U},
\end{gathered}
$$




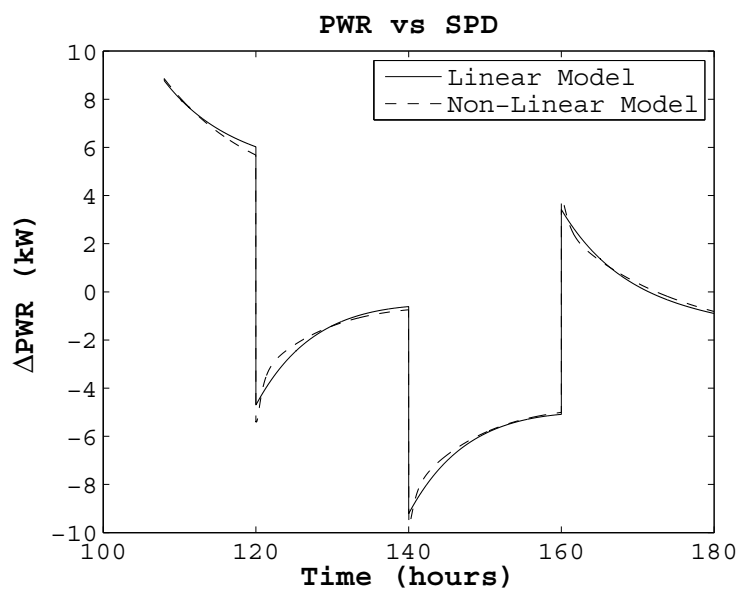

Figure 3: Fit of the PWR/SPD transfer function $\left(g_{44}(s)\right)$ based on the step response validation data.

$$
\begin{aligned}
& \mathbf{y}=\mathbf{g}\left(\mathbf{x}_{0}, \mathbf{u}\right), \\
\mathbb{Y}= & \left\{\mathbf{y} \in \mathbb{R}^{n_{y}} \mid \mathbf{y}_{l} \leq \mathbf{y} \leq \mathbf{y}_{u}\right\}, \\
\mathbb{U}= & \left\{\mathbf{u} \in \mathbb{R}^{n_{u}} \mid \mathbf{u}_{l} \leq \mathbf{u} \leq \mathbf{u}_{u}\right\}, \\
|\Delta \mathbf{u}| \leq & \Delta \mathbf{u}_{\max }, \\
V\left(\mathbf{u}, \mathbf{x}_{0}\right)= & \sum_{i=1}^{N_{p}}\left(\mathbf{Y}_{s p}-\mathbf{y}\right)^{T} \mathbf{Q}\left(\mathbf{Y}_{s p}-\mathbf{y}\right) \\
& +\sum_{i=1}^{N_{c}} \Delta \mathbf{u}^{T} \mathbf{R} \Delta \mathbf{u},
\end{aligned}
$$

where $\mathbf{u}$ represents the manipulated variables, $\mathbf{x}$ the states with initial states $\mathbf{x}_{0}, \mathbf{y}$, the controlled variables, and $\mathbf{Y}_{s p}$ the set-points.

The constraints for the CVs are given by $\mathbf{y}_{u}$ and $\mathbf{y}_{l}$ respectively. The upper constraints of the MVs are given by $\mathbf{u}_{u}$ and the lower constraints by $\mathbf{u}_{l}$. The maximum rate constraints on the MVs are given by

$$
\Delta \mathbf{u}_{\max }=\left[\begin{array}{llll}
1.00 & 0.08 & 1.00 & 0.005
\end{array}\right]^{\mathrm{T}}
$$


The matrices $\mathbf{Q}$ and $\mathbf{R}$ are diagonal weighting matrices for the controlled and manipulated variables respectively. The weights are given in Table 3.

The weights were chosen to achieve the control objectives listed in Section 2.3. The MV weights were chosen so that CFF and SFW are preferentially used by setting their respective weights lowest. MFS has a slightly higher weight, while SPD has the highest weight so as to discourage changes in mill speed.

The effect of SLEV and LOAD set-point deviations on the objective function were set to approximately 20 times less than that of PSE and PWR set-point deviations. The effect of PSE and PWR set-point deviations on the objective function were made equivalent. These weight choices resulted in slightly detuned sump level and mill load control while implementing tight control on particle size and mill power.

The sampling time of the controller, $\Delta T_{M P C}$, is $10 \mathrm{~s}$ (Craig \& MacLeod, 1995). Based on MPC tuning guidelines the prediction horizon, $N_{p}$, should cover the largest settling time, $T_{s}$, of the plant $\left(N_{p}=T_{s} / \Delta T_{M P C}\right)$ (Seborg et al., 2004). The largest settling time is approximately $28 \mathrm{~h}$ for the LOAD/SPD transfer function which relates to a prediction horizon of 10000 moves. Such a large prediction horizon is computationally infeasible.

The sampling time of the controller cannot be increased much from $10 \mathrm{~s}$ as the dynamics between the MVs and SLEV are relatively fast. For example, if $\mathrm{CFF}$ is at the maximum constraint $\left(500 \mathrm{~m}^{3} / \mathrm{h}\right)$ and $\mathrm{SFW}$ at its minimum constraint $\left(0 \mathrm{~m}^{3} / \mathrm{h}\right)$, it will take $134 \mathrm{~s}$ for the sump to run dry if the SLEV was at the nominal value of $18.6 \mathrm{~m}^{3}$. Significantly increasing the sampling interval will therefore result in the violation of control objective (1). A trade- 
off must be made between the fast and slow dynamics of the milling circuit unless a multirate controller is implemented (Halldorsson et al., 2005).

The choice of prediction horizon was modified to be based on the longest settling time between PSE and the MVs. The prediction horizon was therefore chosen as 830 moves, corresponding to $2.3 \mathrm{~h}$, the settling time for the PSE/SPD transfer function. This choice of prediction horizon resulted in a computationally intensive controller. The prediction horizon was iteratively shortened to determine the shortest horizon that achieved similar results. The final prediction horizon that satisfied the control objectives as given in Section 2.3 was $N_{p}=40$.

The number of control moves, $N_{c}$, should be chosen to be small enough to prevent the controller from being too aggressive but large enough such that a sufficient portion of the prediction horizon contains control action (Seborg et al., 2004). The control horizon was therefore chosen as $N_{c}=4$. Blocking is implemented to distribute the control moves over the prediction horizon. The blocking vector that is used is $\left[\begin{array}{llll}4 & 8 & 12 & 16\end{array}\right]$, allowing each successive control move to persist for a longer period than the last.

\section{Supervisory control}

In order to choose the set-points for the mill power load shifting controller, a non-linear cost function was developed to be minimized. The cost function was developed as a loss function based on turnover and the costs associated with electricity consumption. The supervisory control layer has a sampling time $\Delta T_{R T O}=30 \mathrm{~min}$, while the regulatory control layer has a sampling time $\Delta T_{M P C}=10 \mathrm{~s}$. 
Table 4: Variables used for the supervisory control cost function

\begin{tabular}{|c|c|c|}
\hline Variable & Units & Description \\
\hline$L\left(\mathbf{u}_{S S}, \mathbf{y}_{S S}\right)$ & US\$ & $\begin{array}{l}\text { Loss as a function of steady-state MVs } \\
\text { and CVs. }\end{array}$ \\
\hline$I_{t}\left(\mathbf{u}_{S S}, \mathbf{y}_{S S}\right)$ & US\$ & $\begin{array}{l}\text { Turnover as a function of steady state } \\
\text { MVs and CVs. }\end{array}$ \\
\hline$C_{t}\left(\mathbf{y}_{S S}\right)$ & US\$ & $\begin{array}{l}\text { Electricity cost as a function of steady- } \\
\text { state CVs. }\end{array}$ \\
\hline$N$ & $\mathrm{~h}$ & $\begin{array}{l}\text { Window over which } L\left(\mathbf{u}_{S S}, \mathbf{y}_{S S}\right) \text { is eval- } \\
\text { uated. }\end{array}$ \\
\hline$\Delta T_{R T O}$ & $\mathrm{~h}$ & Sampling interval of the RTO. \\
\hline$H G$ & $g / t$ & Approximate head grade of ore. \\
\hline$P_{A D J}$ & $\$ / g$ & $\begin{array}{l}\text { Price of the product at the output of the } \\
\text { flotation process. }\end{array}$ \\
\hline$P_{\text {market }}$ & $\$ /$ troy oz & Market price for platinum. \\
\hline$u_{S S_{2}}$ & $\mathrm{t} / \mathrm{h}$ & $\begin{array}{l}\text { Steady-state feed-rate of ore to the mill } \\
\left(M F S_{S S}\right) \text {. }\end{array}$ \\
\hline$y_{S S_{1}}$ & $\%$ & $\begin{array}{l}\text { Steady-state product particle size } \\
\left(P S E_{S S}\right) .\end{array}$ \\
\hline$y_{S S_{4}}$ & $\mathrm{~kW}$ & Steady-state mill power draw ( $\left.P W R_{S S}\right)$. \\
\hline$\vartheta\left(y_{S S_{1}}\right)$ & $\%$ & $\begin{array}{l}\text { Recovery within flotation process as a } \\
\text { function of } P S E_{S S} \text {. }\end{array}$ \\
\hline$c(t)$ & $\$ / \mathrm{kWh}$ & Electricity tariff at time $t$ \\
\hline
\end{tabular}

\subsection{Cost function}

The cost function is given by

$$
L\left(\mathbf{u}_{S S}, \mathbf{y}_{S S}\right)=\sum_{t=1}^{N / \Delta T_{R T O}}\left[C_{t}\left(\mathbf{y}_{S S}\right)-I_{t}\left(\mathbf{u}_{S S}, \mathbf{y}_{S S}\right)\right]
$$

where $C_{t}(\mathbf{y})$ is the cost associated with electricity consumption, $I_{t}(\mathbf{u}, \mathbf{y})$ is the turnover to which the ROM ore milling circuit contributes, and $N$ is the window over which the cost function is evaluated. The turnover and electricity cost functions are discussed below. The variables used for the turnover and electricity cost function are summarized in Table 4. 


\subsubsection{Turnover}

The turnover associated with the milling circuit product is given by

$$
I_{t}\left(\mathbf{u}_{S S}, \mathbf{y}_{S S}\right)=\Delta T_{R T O} \times H G \times P_{A D J} \times u_{S S_{2}}(t) \times \vartheta\left(y_{S S_{1}}(t)\right),
$$

where $\Delta T_{R T O}$ is the sampling interval in hours, $H G$ is the approximate head grade of the mined ore given as $3 \mathrm{~g} / \mathrm{t}, u_{S S_{2}}$ is the steady-state feed-rate of ore to the mill (MFS) which relates to the throughput over an hour, and $\vartheta\left(y_{S S_{1}}(t)\right)$ is the recovery in percent within the flotation circuit as a function of steady-state PSE $\left(y_{S S_{1}}\right)$. The relationship between recovery and particle size, as given in Fig. 2, is

$$
\vartheta\left(y_{S S_{1}}(t)\right)=-0.009776 y_{S S_{1}}^{2}(t)+1.705 y_{S S_{1}}(t)-2.955 .
$$

The mineral price, $P_{A D J}$, is the price of the product at the output of the flotation circuit. The price is adjusted from the market price of refined platinum to the separated product, or concentrate, produced by the flotation circuit. This adjustment is made so that a comparison of the electricity costs of only the milling circuit can be made to the income associated with the process itself. The adjusted price is given by

$$
P_{A D J}=(0.032) \times(0.75) \times P_{\text {market }},
$$

where 0.032 is the conversion factor between gram and troy ounce, 0.75 represents the percentage of the costs associated with the mining, liberation, and separation processes upstream of the refining process (Cramer, 2008), and $P_{\text {market }}$ is the market price for platinum, given as $\$ 1600 /$ troy oz. 
Table 5: Eskom time-of-use periods (Eskom, 2012b)

\begin{tabular}{cccc} 
Period & Weekdays & Saturdays & Sundays \\
\hline 00:00- 06:00 & Off-peak & Off-peak & Off-peak \\
06:00-07:00 & Standard & Off-peak & Off-peak \\
07:00-10:00 & Peak & Standard & Off-peak \\
10:00-12:00 & Standard & Standard & Off-peak \\
12:00-18:00 & Standard & Off-peak & Off-peak \\
18:00-20:00 & Peak & Standard & Off-peak \\
20:00-22:00 & Standard & Off-peak & Off-peak \\
22:00-24:00 & Off-peak & Off-peak & Off-peak \\
\hline
\end{tabular}

Table 6: Eskom time-of-use tariffs ( $\$ / \mathrm{kWh})$ (Eskom, 2012b)

\begin{tabular}{ccc} 
Period & $\begin{array}{c}\text { High demand season } \\
\text { (Jun.-Aug.) }\end{array}$ & $\begin{array}{c}\text { Low demand season } \\
\text { (Sep.-May) }\end{array}$ \\
\hline Peak & 0.2303 & 0.0644 \\
Standard & 0.0600 & 0.0395 \\
Off-peak & 0.0321 & 0.0277 \\
\hline
\end{tabular}

\subsubsection{Electricity costs}

Electricity consumption is calculated based on the average mill power draw every half hour. Electricity cost is then calculated based on the half hourly electricity consumption billed at the applicable TOU tariff for that half hour. This function is given by

$$
C_{t}\left(\mathbf{y}_{S S}\right)=\Delta T_{R T O} \times y_{S S_{4}}(t) \times c\left(t \times \Delta T_{R T O}\right),
$$

where $y_{S_{S}}$ is the steady-state mill power draw given by $P W R$ in (4) and $c\left(t \times \Delta T_{R T O}\right)$ is the applicable TOU tariff for the given period in US\$ as given in Tables 5 and 6 .

\subsection{Constraints}

The cost function (16) is related here to the milling circuit model by obtaining the steady-state of the linear model (5) used for the controller. The 
steady-state models for the transfer functions $g_{21}(s), g_{22}(s), g_{23}(s), g_{31}(s)$, $g_{32}(s), g_{33}(s)$, and $g_{34}(s)$ were calculated as the gain at the end of the sampling interval $(t=30 \mathrm{~min})$ as these transfer functions contain integrators. The steady-state model is given by

$$
\mathbf{y}_{S S}=\mathbf{G}_{S S} \cdot \mathbf{u}_{S S}
$$

where $\mathbf{G}_{S S}$ is given by

$$
\left[\begin{array}{cccc}
-7.0 \times 10^{-3} & -9.5 \times 10^{-2} & 4.5 \times 10^{-2} & 0.11 \\
8.1 \times 10^{-2} & 4.8 \times 10^{-2} & -7.0 \times 10^{-2} & -1.1 \\
-0.39 & 0.44 & 0.34 & -0.44 \\
3.6 & 9.0 & 1.6 & 74
\end{array}\right]
$$

In addition to using the steady-state model as equality constraints for the cost function, the input and output constraints had to be included too. The CV constraints used in the cost function were made $10 \%$ tighter than those used by the regulatory MPC controller as given in (13) and Table 3 while the MV constraints remained the same. The resulting CV constraints are given by

$$
\begin{aligned}
\mathbf{y}_{l} & =\left[\begin{array}{llll}
63.0 & 32.0 & 5.6 & 1550
\end{array}\right]^{\mathrm{T}} \\
\mathbf{y}_{u} & =\left[\begin{array}{llll}
87.0 & 48.0 & 34.4 & 1950
\end{array}\right]^{\mathrm{T}} .
\end{aligned}
$$

In addition to the constraints on the controlled and manipulated variables, the average throughput was implemented using an equality constraint. The average throughput refers to the throughput over the seven day period for which the optimization is done. The throughput constraint is implemented as

$$
T P T_{\text {ave }} \times 24 \times 7=\sum_{t=1}^{N / \Delta T_{R T O}} \Delta T_{R T O} \times u_{S S_{2}}(t)
$$


where $T P T_{\text {ave }}$ is the average throughput over the seven day period $(24 \mathrm{~h} \times 7)$ and $u_{S S_{2}}(t)$ is the steady-state feed-rate of ore to the milling circuit $\left(M F S_{S S}\right)$ at time $t$.

The throughput constraint originates from the assumption that ore can be supplied to the milling circuit at a certain rate, i.e. a buffer in the form of a silo or storage facility lies between the source of ore and the milling circuit. The average throughput rate of the milling circuit must therefore be the same as the average feed-rate of ore supplied to the milling circuit over a seven day period.

\subsection{Real-time optimizer}

In order to take dynamic changes in the mineral price, electricity price, and throughput availability into account, the loss minimization function is implemented as a real-time optimizer (RTO). The formulation of the RTO is as follows

$$
\begin{gathered}
\min _{\mathbf{u}_{S S}} L\left(\mathbf{u}_{S S}, \mathbf{y}_{S S}\right), \\
\text { s.t. } \mathbf{y}_{S S} \in \mathbb{Y}, \mathbf{u}_{S S} \in \mathbb{U}, \\
\mathbb{Y}=\left\{\mathbf{y}_{S S} \in \mathbb{R}^{n_{y}} \mid \mathbf{y}_{l} \leq \mathbf{y}_{S S} \leq \mathbf{y}_{u}\right\}, \\
\mathbb{U}=\left\{\mathbf{u}_{S S} \in \mathbb{R}^{n_{u}} \mid \mathbf{u}_{l} \leq \mathbf{u}_{S S} \leq \mathbf{u}_{u}\right\}, \\
\left|\Delta \mathbf{u}_{S S}\right| \leq \Delta T_{R T O} / \Delta T_{M P C} \times \Delta \mathbf{u}_{\max }, \\
T P T_{\text {ave }}=\frac{1}{168} \times \sum_{t=1}^{168 / \Delta T_{R T O}} \Delta T_{R T O} \times u_{S S_{2}}(t) .
\end{gathered}
$$

The RTO is implemented with a sampling interval, $\Delta T_{R T O}$, of $30 \mathrm{~min}$. The minimization of the cost function was formulated with a window of $N=168 \mathrm{~h}$ (7 days). The window is made this length in order to take advantage of the cheaper electricity over weekends where throughput can be 
Table 7: Optimal set-points

\begin{tabular}{cccccc} 
Period & Season & PSE & LOAD & SLEV & PWR \\
\hline \multirow{2}{*}{$\mathrm{P}$} & $\mathrm{H}$ & 81.2 & 32.0 & 5.71 & 1550 \\
& $\mathrm{~L}$ & 81.5 & 32.0 & 5.71 & 1701 \\
$\mathrm{~S}$ & $\mathrm{H}$ & 81.8 & 32.0 & 5.75 & 1794 \\
& $\mathrm{~L}$ & 81.9 & 32.0 & 5.73 & 1809 \\
\multirow{2}{*}{ OP } & $\mathrm{H}$ & 82.9 & 32.0 & 5.78 & 1950 \\
& $\mathrm{~L}$ & 82.8 & 32.0 & 5.75 & 1939 \\
\hline
\end{tabular}

increased to compensate for the lower throughput during the week where electricity is on average more expensive.

\subsection{Resulting set-points}

The optimal set-points, $\mathbf{Y}_{s p}$, resulting from the optimal steady-state inputs, $\mathbf{u}_{\text {SSopt }}$, are calculated from

$$
\mathbf{Y}_{s p}=\mathbf{G}_{S S} \cdot \mathbf{u}_{S S o p t} .
$$

The set-points calculated by the RTO for an average weekly throughput of $90 \mathrm{t} / \mathrm{h}$ and the electricity tariffs given in Table 6 are presented in Table 7 where P, S, and OP represent the peak, standard, and off-peak tariff periods respectively. $\mathrm{H}$ and $\mathrm{L}$ represent the high and low demand seasons respectively. The throughput of $90 \mathrm{t} / \mathrm{h}$ was chosen arbitrarily for the purposes of this study. In an industrial setting it will be chosen to meet particular production targets.

\subsubsection{Set-point implementation}

The RTO calculates optimal set-points for PSE, LOAD, SLEV, and PWR. Implementing all four optimal set-points simultaneously decreases the stability of the ROM ore milling circuit. As discussed in Section 2.3, it is important 
to minimize variations in PSE as well as maintain milling circuit stability. The PSE set-point should be chosen in order to maximize recovery downstream from the milling circuit, i.e. the set-point should be $87 \%$ to achieve maximum flotation recovery as indicated in Figure 2. Theoretically speaking therefore the PSE set-point should be kept at this nominal value. There is however a trade-off between PSE and throughput (Bauer \& Craig, 2008), i.e. the higher the PSE the lower the throughput, resulting in a milling circuit usually being operated below the maximum recovery PSE value. The RTO results therefore show that the PSE should be $81.2 \%, 81.8 \%$, and $82.9 \%$ during peak, standard, and off-peak periods respectively. To reduce variations in PSE though, the PSE set-point is maintained at $82 \%$ which lies in the middle of the range of the RTO results.

Additional design choices were made to improve milling circuit stability. The set-points of LOAD and SLEV were maintained at the nominal values, which are in the middle of the respective operating regions. By maintaining the sump level set-point and marginally relaxing sump level control, control of particle size is improved. Similarly maintaining the mill load set-point while allowing increased variations in mill load, improves control of particle size and mill power.

The only set-point that is changed is the mill power set-point.

\subsubsection{Set-point filtering}

Mill power set-point changes are filtered using a first-order filter. Without filtering, step and ramp function mill power set-point changes result in the sump running dry. The set-point change filter (with the time constant in 
hours) is given by

$$
G_{P W R}(s)=\frac{1}{0.1 s+1} .
$$

Using the set-point filter for mill power with the designed time constant allows the set-point to settle in approximately $0.4 \mathrm{~h}$.

\section{Results}

\subsection{Simulation setup}

Simulations were performed on the non-linear ROM ore milling circuit model using the linear model predictive controller described in Sections 2.2 and 3.2 respectively. Three sets of simulations were performed. Measurement noise was simulated through additive Gaussian white noise on each of the outputs.

The first simulation was performed to determine the power consumption for maximum throughput without mill power load shifting. The second simulation was used to determine the baseline power consumption when no mill power load shifting was performed. The third simulation was performed with mill power load shifting aimed at maximizing profit. For the simulations, profit is considered as the turnover less the operating costs for electricity consumption.

\subsubsection{Fixed power simulations}

The maximum achievable average throughput for the milling circuit model is approximately $97 \mathrm{t} / \mathrm{h}$. The mill power associated with a throughput of $97 \mathrm{t} / \mathrm{h}$ is approximately $1950 \mathrm{~kW}$, which was chosen as the power set-point for the maximum throughput simulation. 
The average throughput of $90 \mathrm{t} / \mathrm{h}$ that was arbitrarily chosen for the baseline simulation relates to $93 \%$ of the maximum average throughput of the milling circuit. The baseline simulation was performed to evaluate the performance of mill power load shifting on a milling circuit not running at maximum throughput. The mill power associated with a throughput of $90 \mathrm{t} / \mathrm{h}$ is approximately $1850 \mathrm{~kW}$, which was chosen as the power set-point. The CVs and MVs for the fixed power simulations are not shown in this paper.

A number of factors can affect the average throughput at which a milling circuit operates. These factors include low availability of ore from the mine, restricted throughput of the downstream processes, and even attempts to reduce operating costs.

\subsubsection{Mill power load shifting simulation}

The set-points for the mill power load shifting simulation were calculated using the RTO. The average weekly throughput was chosen as $90 \mathrm{t} / \mathrm{h}$ (the same as the baseline simulation) so that comparisons could be made between the mill power load shifting simulation and the baseline simulation. The controlled variables for the mill power load shifting simulation over a oneweek period (168 h) during the high demand season are presented in Fig. 4 and the manipulated variables in Fig. 5. The controlled and manipulated variables for the low demand season are given in Fig. 6 and 7 respectively.

\subsection{Simulation results}

The simulation results are presented as electricity cost savings, throughput losses, and cost improvement per unit of unrefined platinum. 

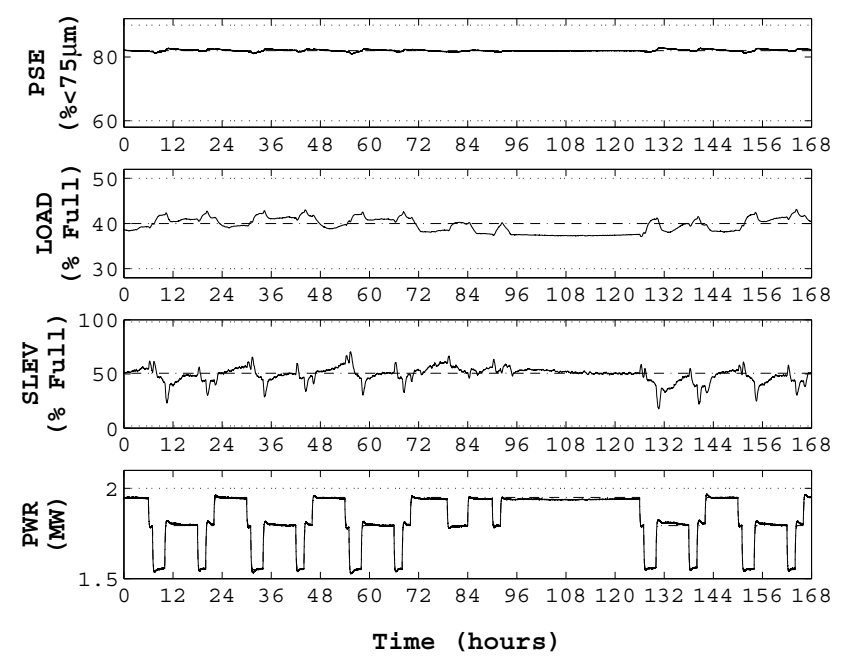

Figure 4: Controlled variables for the high demand mill power load shifting simulation. The solid lines indicate the CVs, the dash-dotted lines the set-points, and the dashed lines the constraints.
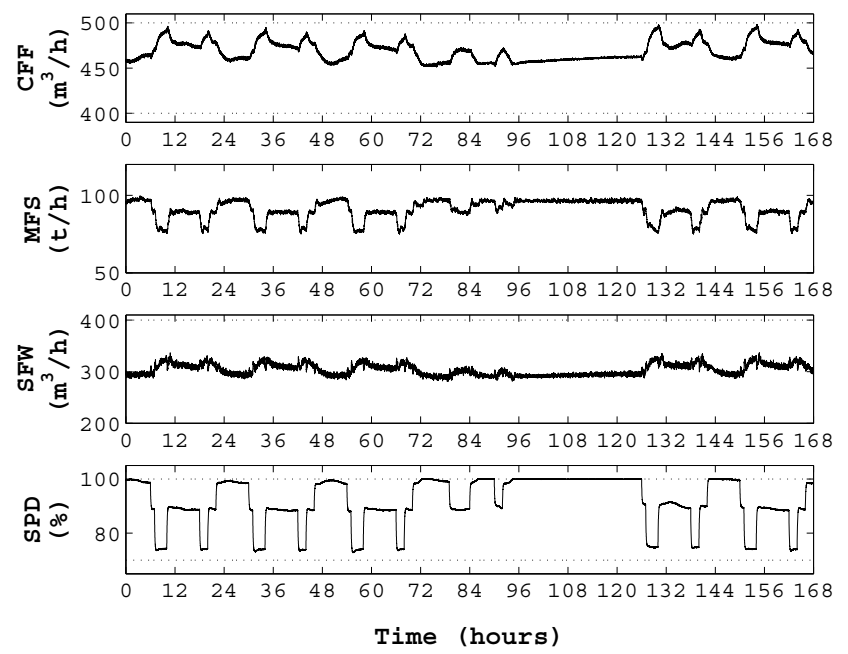

Figure 5: Manipulated variables for the high demand mill power load shifting simulation. The solid lines indicate the MVs and the dashed lines the constraints. 

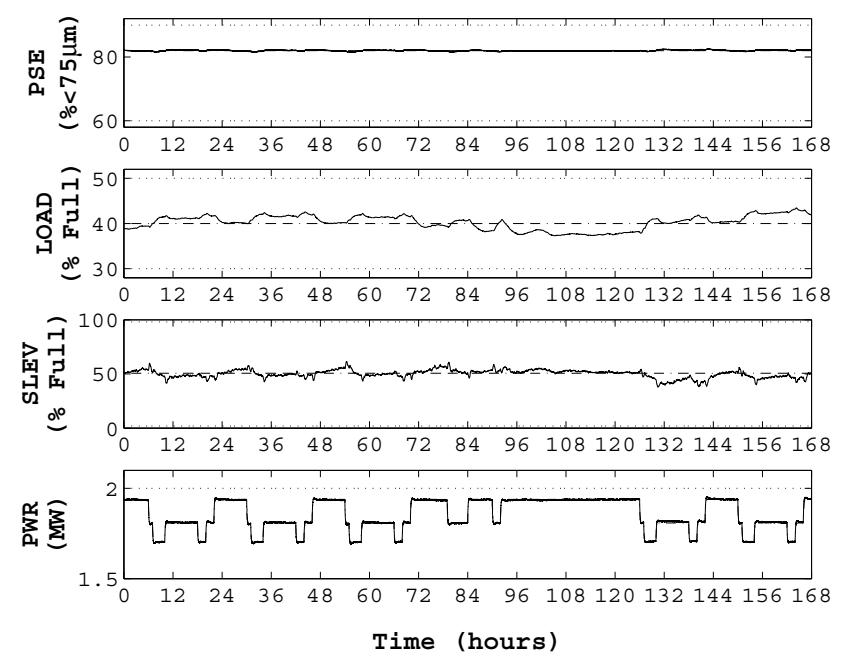

Figure 6: Controlled variables for the low demand mill power load shifting simulation. The solid lines indicate the CVs, the dash-dotted lines the set-points, and the dashed lines the constraints.
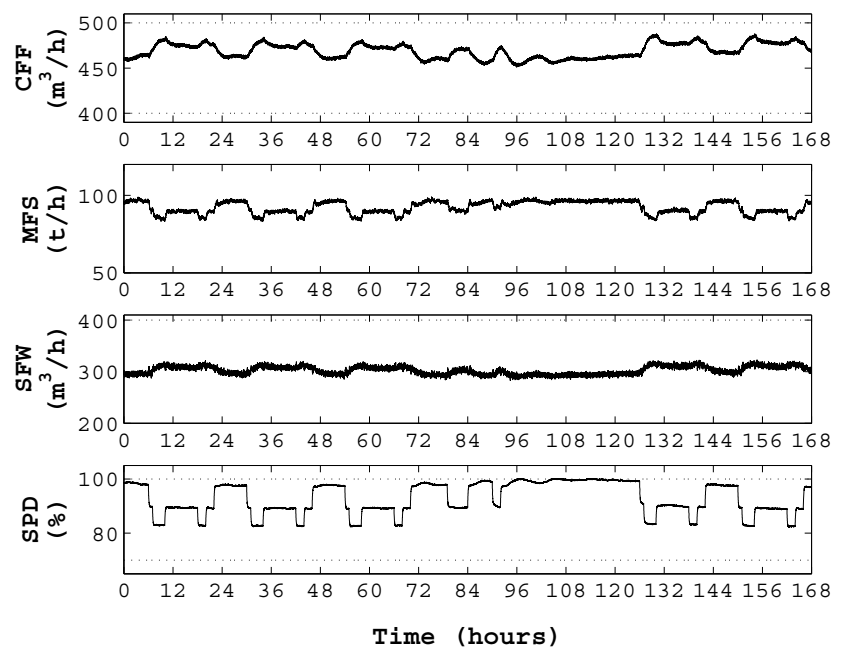

Figure 7: Manipulated variables for the low demand mill power load shifting simulation. The solid lines indicate the MVs and the dashed lines the constraints. 
Table 8: Electricity costs (US\$/week)

\begin{tabular}{ccc} 
Simulation & $\begin{array}{c}\text { High demand } \\
\text { season }\end{array}$ & $\begin{array}{c}\text { Low demand } \\
\text { season }\end{array}$ \\
\hline Max Throughput & $13,032.30$ & $6,783.39$ \\
Baseline & $12,418.98$ & $6,464.08$ \\
Load Shifting & $11,965.05$ & $6,369.86$ \\
\hline
\end{tabular}

\subsubsection{Electricity cost reduction}

The electricity costs are calculated by taking the average power consumption of the mill every hour and billing it at the relevant TOU tariff. The total electricity cost is then calculated by summing the hourly electricity cost over the simulation horizon. Total electricity cost is given by

$$
C_{t o t}=\sum_{t=1}^{168}\left[c(t) \times \Delta T_{M P C} \sum_{i=0}^{1 / \Delta T_{M P C}-1}\left[P W R\left(t+i / \Delta T_{M P C}\right)\right]\right]
$$

where $P W R\left(t+i / \Delta T_{M P C}\right)$ is the mill power at sampling instant $t+i / \Delta T_{M P C}$, $c(t)$ is the TOU tariff applicable at time $t$ as given in Table 6 , and $\Delta T_{M P C}$ is the sampling interval of the MPC controller.

The electricity costs, in US dollars per week, for each of the simulations are given in Table 8 . The electricity cost for the mill power load shifting simulation is lower than the two fixed power simulations as would be expected. The electricity costs for the high demand season are approximately twice the costs for the low demand season.

\subsubsection{Throughput losses}

The average throughput achieved for both the baseline and mill power load shifting simulations was $90.94 \mathrm{t} / \mathrm{h}$. The average throughput achieved for the maximum throughput simulation was $96.80 \mathrm{t} / \mathrm{h}$. The income based 
Table 9: Income (US\$/week)

\begin{tabular}{cc} 
Simulation & Income \\
\hline Max Throughput & $1,338,599$ \\
Baseline & $1,257,745$ \\
Load Shifting & $1,257,794$ \\
\hline
\end{tabular}

on average throughput and product particle size were calculated by

$$
I_{\text {tot }}=168 \times H G \times P_{A D J} \times T P T_{\text {achieved }} \times \vartheta\left(P S E_{\text {achieved }}\right),
$$

where $T P T_{\text {achieved }}$ is the average throughput over the simulation horizon given by

$$
T P T_{\text {achieved }}=168 / \Delta T_{M P C} \sum_{t=1}^{168 / \Delta T_{M P C}}\left[T P T\left(t / \Delta T_{M P C}\right)\right] .
$$

$P S E_{\text {achieved }}$ is the average product particle size over the simulation horizon given by

$$
P S E_{\text {achieved }}=168 / \Delta T_{M P C} \sum_{t=1}^{168 / \Delta T_{M P C}}\left[P S E\left(t / \Delta T_{M P C}\right)\right] .
$$

$H G$ is the head grade of the mined ore given as $3 \mathrm{~g} / \mathrm{t}, P_{A D J}$ is the adjusted price as in $(19)$, and $\vartheta\left(P S E_{\text {achieved }}\right)$ is the recovery based on average PSE given by (18). The weekly income based on the average throughput and product particle size for each simulation is presented in Table 9.

\subsubsection{Cost improvement per unit production}

The cost improvement per unit production is based on only the baseline and mill power load shifting simulations as the throughput achieved for each of the simulations was the same. The cost improvement was calculated using

$$
C_{\text {improvement }}=\frac{\left[C_{\text {tot(baseline })}-C_{\text {tot(load shifting })}\right]}{T P T_{\text {achieved }} \times H G},
$$


where $T P T_{\text {achieved }}$ is the weekly throughput achieved $(15278 \mathrm{t}), H G$ is the head grade $(3 \mathrm{~g} / \mathrm{t}), C_{\text {tot(baseline) }}$ is the total weekly electricity cost for the baseline simulation, and $C_{\text {tot(loadshifting) }}$ is the total weekly electricity cost for the mill power load shifting simulation. The cost improvement was calculated as $\$ 9.90$ and $\$ 2.05$ per kilogram of unrefined platinum produced for the high and low demand season respectively.

\subsubsection{Ore inventory storage}

When performing power load shifting it is necessary to have some storage facility, such as a silo, that acts as a buffer between the upstream ore supply and the milling circuit. It is generally not economically feasible to perform mill power load shifting on a milling circuit where the upstream ore supply is higher than the average throughput of the circuit as is illustrated in Section 5.2.2, and this case will therefore not be considered.

The RTO is designed to take the upstream ore supply into account and match the average milling circuit throughput to the supply of ore while minimizing the cost function. The storage facility is therefore only necessary for storing ore when the circuit throughput is reduced during peak tariff periods and then increased during off-peak periods. The change in the holdup of ore within the silo can be given by

$$
\frac{d X_{s o}}{d t} \triangleq V_{s i}-V_{s o}
$$

where $X_{s o}[\mathrm{t}]$ is the holdup of ore within the silo $\left(X_{s o}(0)=0\right), V_{s i}[\mathrm{t} / \mathrm{h}]$ is the feed-rate of ore from upstream into the silo chosen to be $90.94 \mathrm{t} / \mathrm{h}$, and $V_{s o}[\mathrm{t} / \mathrm{h}]$ is the feed-rate of ore to the milling circuit $\left(V_{s o}=M F S\right)$.

The maximum additional holdups of ore within the silo for the high and 
low demand season mill power load shifting simulations are $249.5 \mathrm{t}$ and $173.0 \mathrm{t}$ respectively. The daily average throughput for both mill power load shifting simulations is $2182.6 \mathrm{t}$. The maximum holdup within the silo is therefore $11.4 \%$ and $7.9 \%$ of the daily average throughput for the high and low demand season simulations respectively.

If the stockpile is sized such that the safety stock covers one week's worth

of production or 15278.2 t, (Jacobs et al., 2009), the maximum additional holdups owing to DSM are $1.6 \%$ and $1.1 \%$ of the week's safety stock capacity for the high and low demand seasons respectively. Such a small increase in inventory should not lead to any additional inventory storage costs.

\subsubsection{Milling circuit stability}

As can be observed in Fig. 4 and 6, the controlled variables remained comfortably within the constraints for the mill power load shifting simulation. The control over product particle size remained tight with a mean of 82.03, and standard deviation of 0.0031 .

The manipulated variables $\mathrm{CFF}$, MFS, and SFW remain comfortably within their constraints. This indicates that the controller is not running at its limit and has room to maneuver if disturbances are introduced (Olivier et al., 2012).

\subsubsection{Disturbances}

Disturbances were not introduced for the simulations performed as much work has been done in the area of disturbance rejection. MPC is sensitive to large disturbances and disturbance observers have been developed that significantly attenuate the effect of disturbances on milling circuits (Olivier 
et al., 2012; Yang et al., 2010).

\section{Conclusion}

It has been shown that by controlling mill power using mill speed that the operating costs attributed to power consumption can be reduced without sacrificing product quality. The control of mill power was implemented using a linear model predictive controller on a non-linear plant model.

The results of the simulation study indicate that performing mill power load shifting on a milling circuit not running at full capacity is more cost effective than simply running at a lower mill power. With increasing electricity costs this is an important consideration.

The simulations show that for a $2 \mathrm{MW}$ mill running at approximately $93 \%$ of achievable capacity, a cost saving of $\$ 9.90 / \mathrm{kg}$ of unrefined platinum can be achieved using mill power load shifting. For mills that run at maximum throughput capacity mill power load shifting is not necessarily economically feasible as the income associated with the additional product produced has a larger effect on profitability than the cost of electricity.

For mines that implement power scheduling the benefits of mill power load shifting should also be evaluated according to maximum demand charges. In order to evaluate the maximum demand charges, the maximum demand of already implemented scheduling operations should be added to the maximum demand for mill power load shifting.

The advantage of using an RTO is that the optimizer is run on-line and can take changes in ore availability into account. The RTO can also take dynamic changes of electricity cost and mineral price into account. Though 
the profitability can be added to an MPC cost function, using an RTO allows for a decoupling between economic objectives and control objectives in the supervisory and regulatory control layers respectively.

By using this regulatory/supervisory control layer approach with a controller and RTO the stability of the system can be prioritized. Economic optimization can then be performed when the system is stable without requiring a trade-off between stability and economic performance.

Implementation of mill power load shifting is dependent on the milling circuit design. An ore supply storage facility is needed to buffer the ore supply during the week when electricity is expensive and throughput is reduced. For a controller that controls mill power based on mill speed it is necessary that the mill motor is equipped with a variable speed drive. Finally it is necessary to have an accurate real-time measurement of product particle size.

\section{References}

Badenhorst, W., Zhang, J., \& Xia, X. (2011). Optimal hoist scheduling of a deep level mine twin rock winder system for demand side management. Electr. Power Syst. Res., 81, 1088-1095.

Bauer, M., \& Craig, I. K. (2008). Economic assessment of advanced process control - a survey and framework. J. Process Control, 18, 2-18.

Borell, M., Bäckström, P.-O., \& Söderberg, L. (1996). Supervisory control of autogenous grinding circuits. Int. J. Miner. Process., 44-45, $337-348$.

Chen, X. S., Li, Q., \& Fei, S. M. (2008). Constrained model predictive control in ball mill grinding process. Powder Technol., 186, 31-39. 
Chen, X. S., Zhai, J. Y., Li, S. H., \& Li, Q. (2007). Application of model predictive control in ball mill grinding circuit. Miner. Eng., 20, 1099-1108.

Coetzee, L. C. (2009). Robust nonlinear model predictive control of a closed run-of-mine ore milling circuit. Ph.D. thesis University of Pretoria.

Coetzee, L. C., Craig, I. K., \& Kerrigan, E. C. (2010). Robust nonlinear model predictive control of a run-of-mine ore milling circuit. IEEE Trans. Control Syst. Technol., 18, 222-229.

Craig, I. K., Hulbert, D. G., Metzner, G., \& Moult, S. P. (1992). Optimized multivariable control of an industrial run-of-mine milling circuit. J. S. Afr. Inst. Min. Metall., 92, 169-176.

Craig, I. K., \& MacLeod, I. M. (1995). Specification framework for robust control of a run-of-mine ore milling circuit. Control Eng. Pract., 3, 621630 .

Cramer, L. A. (2008). What is your PGM concentrate worth? In 3rd Int. Platin. Conf. Platinum in Transformation, SAIMM, Sun City, South Africa (pp. 387-394).

Eskom (2012a). Integrated report for the year ended 31 March 2012. Web site: http://www.financialresults.co.za/2012/eskom_ar2012/ [Last accessed: 01 Nov 2012].

\begin{tabular}{ccccc} 
Eskom & (2012b). & Tariffs & and & charges book- \\
let & 2012/2013. & Web & site: & http://www. \\
\multicolumn{4}{l}{ eskom.co.za/content/ESKOM\%20TC\%20BOOKLET\%202012-13.pdf }
\end{tabular}
[Last accessed: 01 Nov 2012]. 
Gellings, C. W. (1985). Concept of demand-side management for electric utilities. Proc. IEEE, 73, 1468-1470.

Halldorsson, U., Fikar, M., \& Unbehauen, H. (2005). Nonlinear predictive control with multirate optimisation step lengths. IEE Proceedings: Control Theory and Applications, 152, 273-284.

Hodouin, D. (2011). Methods for automatic control, observation, and optimization in mineral processing plants. J. Process Control, 21, 211 225 .

Hulbert, D. G., Craig, I. K., Coetzee, M. L., \& Tudor, D. (1990). Multivariable control of a run-of-mine milling circuit. J. S. Afr. Inst. Min. Metall., 90, 173-181.

Jacobs, F. R., Chase, R. B., \& Aquilano, N. J. (2009). Operations 83 Supply Management. (12th ed.). McGraw-Hill, NY.

Jansen, W. (2012). Quarterly comodity insights buletin q1-2012 - platinum. Web site: http://www.kpmg.com/Global/en/IssuesAndInsights/ ArticlesPublications/commodity-insights-bulletin/Documents/platinumq1- 2012.pdf [Last accessed: 01 Nov 2012].

Le Roux, J. D., Craig, I. K., Hulbert, D. G., \& Hinde, A. L. (2012). Analysis and validation of a run-of-mine ore grinding mill circuit model for process control. Miner. Eng., Article in Press.

Ljung, L. (1999). System Identification Theory for the User. (2nd ed.). Prentice Hall, Upper Saddle River, NJ. 
Middelberg, A., Zhang, J., \& Xia, X. (2009). An optimal control model for load shifting - with application in the energy management of a colliery. Appl. Energy, 86, 1266-1273.

Muller, B., \& De Vaal, P. L. (2000). Development of a model predictive controller for a milling circuit. J. S. Afr. Inst. Min. Metall., 100, 449-453.

NERSA (2012). Reason for decision - The review of the Eskom tariffs for the period 01 April 2012 to 31 March 2013. Technical Report National Energy Regulator of South Africa.

Niemi, A. J., Tian, L., \& Ylinen, R. (1997). Model predictive control for grinding systems. Control Eng. Pract., 5, 271-278.

Olivier, L. E., Craig, I. K., \& Chen, Y. Q. (2012). Fractional order and BICO disturbance observers for a run-of-mine ore milling circuit. J. Process Control, 22, 3-10.

Palensky, P., \& Dietrich, D. (2011). Demand side management: Demand response, intelligent energy systems, and smart loads. IEEE Trans. Ind. Inform., 7, 381-388.

Radhakrishnan, V. R. (1999). Model based supervisory control of a ball mill grinding circuit. J. Process Control, 9, $195-211$.

Ramasamy, M., Narayanan, S. S., \& Rao, C. D. P. (2005). Control of ball mill grinding circuit using model predictive control scheme. J. Process Control, 15, 273-283. 
Seborg, D. E., Edgar, T. F., \& Mellichamp, D. A. (2004). Process Dynamics and Control. (2nd ed.). Wiley, NJ.

Skogestad, S., \& Postlethwaite, I. (2005). Multivariable Feedback Control Analysis and Design. (2nd ed.). Wiley, Chichester.

Steyn, C. W., Brooks, K. S., de Villiers, P. G. R., Muller, D., \& Humphries, G. (2010). A holistic approach to control and optimization of an industrial run-of-mine ball milling circuit. IFAC Autom. Min. Miner. Met. Process., 13, 137-141. doi:10.3182/20100802-3-ZA-2014.00032

van Staden, A. J., Zhang, J., \& Xia, X. (2011). A model predictive control strategy for load shifting in a water pumping scheme with maximum demand charges. Appl. Energy, 88, 4785-4794.

Wei, D., \& Craig, I. K. (2009a). Economic performance assessment of two ROM ore milling circuit controllers. Miner. Eng., 22, 826-839.

Wei, D., \& Craig, I. K. (2009b). Grinding mill circuits - a survey of control and economic concerns. Int. J. Miner. Process., 90, 56-66.

Yang, J., Li, S. H., Chen, X. S., \& Li, Q. (2010). Disturbance rejection of ball mill grinding circuits using DOB and MPC. Powder Technol., 198, 219-228. 